\title{
Identification of Silicone Oil Maculopathy by OCT after Vitrectomy for Rhegmatogenous Retinal Detachment
}

\author{
Ibrahim M. Amer
}

Department of Ophthalmology, Faculty of Medicine, Al-Azhar University, Assuit, Egypt

Corresponding author: Ibrahim Mohamd Ahmed, E-Mail: amer_eye_80@yahoo.com,

Mobile: (+2)01011168920

\section{ABSTRACT}

Background: silicone oil (SO) is used as a vitreous replacement and has been shown to be effective in repairing complicated retinal detachment. Its use, however, may have several disadvantages.

Aim: to study the macular changes after SO injection as tamponade in vitrectomy for rhegmatogenous retinal detachment (RRD). Patients and Methods: a prospective, interventional and non-randomized study was performed on 75 eyes (75 patients) of RRD. The patients underwent primary vitrectomy with SO tamponade. All the patients were examined at baseline and postoperatively at day one, one week, one month, and three months. Each visit examination included best corrected visual acuity (BCVA), indirect ophthalmoscopy slit-lamp biomicroscopy, fundus examination by binocular indirect slit-lamp biomicroscopy, measurement of intraocular pressure, and optical coherent tomography (OCT) at 1,3 months postoperatively. Results: 71 of the 75 eyes, had a successful vitrectomy with reattached retina under SO tamponade and 4 eyes were excluded. The patients' mean age was $48 \pm 4.5$ years. Preoperatively, the macula was on in $41(57.75 \%)$ eyes and off in 30(42.25\%) while retinal detachment (RD) was total in $18(25.35 \%)$ eyes and subtotal in 53(74.65\%) eyes. Central macular thickness (CMT) was 177-850 microns. Three months after vitrectomy, CMT was 154-708 microns. While no statistical significant difference was detected between 1 month to 3 months after vitrectomy $(\mathrm{P}=0.175)$. Postoperative OCT changes include attenuated IS/OS junction in $16(22.54 \%)$ eyes, macular edema in $15(21.13 \%)$ eyes, epiretinal membrane in $13(18.31 \%)$ eyes.

Conclusions: OCT is a beneficial tool for identification of silicone oil maculopathy even in clinically normal maculae. Keywords: Silicone oil, maculopathy, OCT

\section{INTRODUCTION}

Silicone oil (SO) was used as a vitreous substitute since 1960s and proved efficacy as a long term tamponade for repair of complex retinal detachment ${ }^{(\mathbf{1})}$.

Silicone oil is chemically inert ${ }^{(2)}$. However, its use may be associated with several disadvantages including emulsification, cataract, glaucoma, and keratopathies ${ }^{(\mathbf{1 , 3 - 5})}$. Therefore, removal of silicone oil is important to avoid such complications ${ }^{(6,7)}$. In addition, silicone oil may result in microstructural retinal damage $^{(\mathbf{8 , 9})}$ that may affect visual functions ${ }^{(\mathbf{1 0 , 1 1})}$.

Because retinal changes under silicone oil tamponade and after its removal are difficult to evaluate clinically, the utilization of SDOCT scan demonstrate these retinal changes ${ }^{(12)}$. The existence of SO in the vitreous doesn't alter the reproducibility of OCT measurements for foveal thickness ${ }^{(\mathbf{1 3})}$.

Retinal changes resulting from SO injection could manifest in the form of macular dysfunction with lesions in the ganglion cells and horizontal-bipolar cell synapses process in the outer plexiform layer ${ }^{(\mathbf{1 4 , 1 5})}$, epiretinal membrane (ERM), sub silicone membrane and macular hole ${ }^{(16)}$, cystoid macular edema ${ }^{(17)}$, and photoreceptor and nerve fiber layer damage ${ }^{(18,19)}$.

\section{AIM OF THE STUDY}

This study aimed to assess the macular changes after SO injection as tamponade in vitrectomy for rhegmatogenous retinal detachment (RRD).

\section{PATIENTS AND METHODS}

This is a prospective interventional nonrandomized study. It included 75 eyes of RRD without or with proliferative vitreoretinopathy of intermediate severity (PVR up to grade B).

All cases had been underwent primary vitrectomy with silicone oil 2000 centistokes (cSt) tamponade (Geuder silicone oil Siluron $2000 \mathrm{cSt}$ FLUORON GmbH, Germany).

The patients were selected from the Modern Eye Center at Assiut city, where the author practice, from December 2016 to December 2018.

The patients underwent primary vitrectomy with SO tamponade, and investigated by OCT Swept source (SS-OCT) DRI triton OCT (TOPCON, Japan). Ethical and approval consideration:

The protocol was approved by the Ethical Committee of Al-Azhar Faculty of Medicine, Assuit, Al-Azhar University. Then, formal informed consent was taken from each patient.

\section{Inclusion criteria:}

They were patients with RRD (phakic or pseudophakic) with or without PVR of intermediate severity (PVR up to grade B).

\section{Exclusion criteria:}

They were preexisting macular pathology as age-related macular degeneration and macular hole, recurrent retinal detachment following a previous failed vitrectomy, postoperative media opacities interfering with OCT imaging, eyes with uveitis, retinal vascular diseases, optic nerve changes and history of ocular surgery, other than cataract surgery.

\section{Study examinations:}

All the patients were examined at baseline, day one, first week, first month, and 3 months postoperatively. Each visit examination included best 
corrected visual acuity (according to log MAR chart), slit lamp biomicroscopy, measurement of intraocular pressure (IOP), and detailed fundus examination (via dilated pupil) by using binocular indirect slit-lamp biomicroscopy and indirect ophthalmoscopy.

\section{OCT examination:}

OCT Swept source (SS-OCT) DRI triton OCT, TOPCON, Japan) with fully dilated pupil at 1 month and 3 months after vitrectomy.

The OCT macular tomography was interpreted as follows: Macula: radial scan: $1024 \mathrm{x} 6$ or 12 (6 or 12 radial scan lines comprised of $1024 \mathrm{~A}$-scans), $6 \mathrm{~mm}$ and $9 \mathrm{~mm}$. Retinal thickness map internal limiting membrane-retinal pigment epithelium (ILM-RPE) was measured according to ETDRS. The presence or absence of vitreoretinal interface abnormalities, intraretinal fluid and subretinal fluid were evaluated. The status of the photoreceptor inner segment/outer segment (IS/OS) junction and external limiting membrane (ELM) were evaluated in the images as disrupted or complete. The disruption in IS/OS or ELM was known as loss of back-reflection line.

\section{Study procedure: \\ Pars plana vitrectomy:}

Local anesthesia under supervision of anestheologist, to monitor local anesthesia, was performed. Sterilization with betadine $10 \%$ for the eye lids and betadine eye drops $5 \%$ for the surface of the globe. Twenty three $\mathrm{G}$ vitrectomy system was used in 36 eyes, whereas $20 \mathrm{G}$ system was used in 14 eyes. Phakic patients, with any degree of lens opacity, at presbyopic age underwent phacoemulsification and in bag implantation of foldable IOL for proper shaving of the vitreous base and also to ensure clear media for imaging and for proper assessment of the visual acuity. Non-contact wide-angle viewing system (Resight Ziess, Germany) was used for visualization. Vitrectomy (Associate Dual 6000, D.O.R.C., and Netherlands) for the vitreous base was performed meticulously 360 degrees with scleral indentation accomplished by the assistant. Endolaser photocoagulation was used to all retinal breaks at 360 degrees (Laser Star 532, D.O.R.C., Netherlands). Silicone oil was injected as a tamponade (Geuder silicone Siluron 2000 cSt, FLUORON GmbH, Germany). Then air-fluid exchange is followed by airsilicone exchange.

\section{Statistical analysis:}

Date entry and analysis were done using Statistical Package for Social Science (SPSS version 19). Data were presented as number, percentage, mean, standard deviation (SD). Wilcoxon Signed Rank Test was done to compare quantitative variables between 1 and 3 months after vitrectomy.

\section{RESULTS}

This study included 75 eyes (of 75 patients) subjected to primary vitrectomy with SO tamponade following RRD. Seventy one eyes had a successful vitrectomy with reattached retina under SO tamponade and 4 eyes of 4 patients were redetected within 1 month after vitrectomy [subtotal retinal detachment (RD) under SO tamponade] and excluded from the statistics of our study.

Table (1): Personal data of the studied patients

\begin{tabular}{|l|c|c|}
\hline \multicolumn{1}{|c|}{ Variables } & $\begin{array}{c}\text { No. }(\mathbf{n}=\mathbf{7 1}) \\
\text { Age (years) }\end{array}$ & $\%$ \\
\hline$<\mathbf{4 0}$ & 19 & 26.76 \\
\hline $\mathbf{4 0}-\mathbf{5 0}$ & 15 & 21.13 \\
\hline$>\mathbf{5 0}$ & 37 & 52.11 \\
\hline Mean \pm SD & \multicolumn{2}{|c|}{$48 \pm 4.5$} \\
\hline \multicolumn{3}{|c|}{ Sex } \\
\hline Male & 20 & 28.17 \\
\hline Female & 51 & 71.83 \\
\hline
\end{tabular}

The age of patients ranged from 25 to 66 years, with a mean of $48 \pm 4.5$ years. The female to male ratio was $20: 51$ (28.17\% were males and $71.83 \%$ were females) (Table $\mathbf{1})$.

Table (2): Clinical data of patients with RRD

\begin{tabular}{|c|c|c|}
\hline Variables & $\begin{array}{c}\text { No. of eyes } \\
\quad(n=71)\end{array}$ & $\%$ \\
\hline \multicolumn{3}{|c|}{ Macula status } \\
\hline On & 41 & 57.75 \\
\hline Off & 30 & 42.25 \\
\hline \multicolumn{3}{|c|}{ Extent and height of retinal detachment (RD) } \\
\hline Total & 18 & 25.35 \\
\hline Subtotal & 53 & 74.65 \\
\hline \multicolumn{3}{|c|}{ Type of the break } \\
\hline Horse shoe & 59 & 83.1 \\
\hline Giant break & 9 & 12.68 \\
\hline Dialysis & 3 & 4.23 \\
\hline
\end{tabular}

Preoperatively, the macula was on in $41(57.75 \%)$ eyes and off in 30(42.25\%). While RD was total in $18(25.35 \%)$ eyes and subtotal in 53(74.65\%) eyes (table 2 shows the preoperative Macula state, RD break type and its extent).

Type of surgery:

Our study statistics included 41 pseudophakic eyes underwent primary vitrectomy. It included 30 phakic eyes, 18 eyes of them were presented with different degrees of cataract, so underwent phacoemulsification combined with primary vitrectomy and 12 eyes had a clear crystalline lens so underwent primary vitrectomy only. This study included 75 eyes of 75 patients whom underwent primary vitrectomy with or without phacoemulsification and IOL implantation. Four eyes of them (5.33\%) had recurrent subtotal RD under silicone oil tamponade within 1 month after vitrectomy and were excluded from our study statistics. Seventy-one eyes (94.67\%) achieved a complete retinal attachment after vitrectomy with single operation success rate. 
Post- operative data:

Table (3): Best Corrected Visual Acuity (BCVA)

\begin{tabular}{|c|c|c|c|c|c|c|c|c|c|}
\hline \multirow[t]{2}{*}{ BCVA } & \multicolumn{2}{|c|}{$\begin{array}{c}\text { Before } \\
\text { vitrectomy }\end{array}$} & \multicolumn{2}{|c|}{$\begin{array}{l}1 \text { month after } \\
\text { vitrectomy }\end{array}$} & \multicolumn{2}{|c|}{$\begin{array}{c}3 \text { months after } \\
\text { vitrectomy }\end{array}$} & \multirow{2}{*}{$\begin{array}{l}\text { P1- } \\
\text { Value }\end{array}$} & \multirow{2}{*}{$\begin{array}{c}\text { P2- } \\
\text { Value }\end{array}$} & \multirow{2}{*}{$\begin{array}{c}\text { P3- } \\
\text { Value }\end{array}$} \\
\hline & No. & $\%$ & No. & $\%$ & No. & $\%$ & & & \\
\hline 2.00 & 7 & 15.2 & 7 & 15.2 & 4 & 8.7 & 0.771 & 0.520 & 0.520 \\
\hline 1.9 & 5 & 10.9 & 7 & 15.2 & 2 & 4.3 & 0.756 & 0.434 & 0.157 \\
\hline 1.7 & 2 & 4.3 & 2 & 4.3 & 10 & 21.7 & 1.000 & 0.03 & $\mathbf{0 . 0 3}^{*}$ \\
\hline 1.5 & 1 & 2.2 & 1 & 2.2 & 2 & 4.3 & 1.000 & 1.000 & 1.000 \\
\hline 1.3 & 3 & 6.5 & 2 & 4.3 & 3 & 6.5 & 1.000 & 1.000 & 1.000 \\
\hline 0.5 & 4 & 8.7 & 0 & 0.0 & 0 & 0.0 & 0.116 & 0.116 & --- \\
\hline 0.6 & 7 & 15.2 & 7 & 15.2 & 9 & 19.6 & 0.771 & 0.783 & 0.783 \\
\hline 0.8 & 7 & 15.2 & 9 & 19.6 & 10 & 21.7 & 0.783 & 0.591 & 1.000 \\
\hline 1.00 & 10 & 21.7 & 11 & 23.9 & 6 & 13.0 & 1.000 & 0.409 & 0.282 \\
\hline
\end{tabular}

*: Statistical significant difference.

P1: Before vitrectomy \& 1 month after vitrectomy.

P2: Before vitrectomy \& 3 months after vitrectomy.

P3: 1 month after vitrectomy \& 3 months after vitrectomy.

Pre- and post-operative best corrected visual acuities (according to log MAR chart) are presented in table 3. The only significant difference was detected at $1.7 \mathrm{BCVA}$ between before vitrectomy \& 1 month after vitrectomy $(\mathrm{P}=0.03)$ and 1 month after vitrectomy $\& 3$ months after vitrectomy $(\mathrm{P}=0.03)$.

OCT evaluation following surgery:

The central macular thickness (CMT):

CMT is defined as the thickness of the central $1 \mathrm{~mm}$ of the macula. One month after vitrectomy, CMT was ranged from 177 to 850 microns with Mean \pm SD 306.67 \pm 168.49 microns. Three months after vitrectomy, CMT was ranged from 154 to 708 microns with Mean \pm SD $274.76 \pm 106.78$ microns. While no statistical significant difference was detected from 1 month after vitrectomy to 3 months after vitrectomy $(\mathrm{P}=0.175)$ as shown in table (4).

Table (4): Central macular thickness central macular thickness (CMT)

\begin{tabular}{|l|c|c|c|}
\hline & \multicolumn{2}{|c|}{ CMT } & \\
& $\begin{array}{c}\text { 1 month after } \\
\text { Vitrectomy }\end{array}$ & $\begin{array}{c}\text { 3 months after } \\
\text { Vitrectomy }\end{array}$ & $\begin{array}{c}\text { P- } \\
\text { value }\end{array}$ \\
\hline $\begin{array}{l}\text { Mean } \pm \\
\text { SD }\end{array}$ & $306.67 \pm 168.49$ & $274.76 \pm 106.78$ & 0.175 \\
\hline $\begin{array}{l}\text { Median } \\
\text { (range) }\end{array}$ & $250(177-850)$ & $234(154-708)$ & --- \\
\hline
\end{tabular}

Table (5): OCT finding before at 3 months after vitrectomy

\begin{tabular}{|l|c|c|}
\hline \multicolumn{1}{|c|}{ Variables } & $\begin{array}{c}\text { No. } \\
\text { (n=71) }\end{array}$ & $\%$ \\
\hline Normal OCT findings & 25 & 35.21 \\
\hline Attenuated IS/OS and RPE & 16 & 22.53 \\
\hline Epiretinal membrane & 13 & 18.31 \\
\hline $\begin{array}{l}\text { Atrophic maculopathy \& } \\
\text { diffuse thinning of retinal } \\
\text { layers }\end{array}$ & 7 & 9.86 \\
\hline Cystoid macular edema & 7 & 9.86 \\
\hline Localized macular edema & 3 & 4.22 \\
\hline $\begin{array}{l}\text { Diffuse (sponge like thickening) } \\
\text { retinal edema }\end{array}$ & 5 & 7.04 \\
\hline Serous macular detachment & 5 & 7.04 \\
\hline Macular hole & 5 & 7.04 \\
\hline $\begin{array}{l}\text { Corrugated retinal pigment } \\
\text { epithelium }\end{array}$ & 4 & 5.63 \\
\hline Perfluorocarbon under retina & 3 & 4.22 \\
\hline Intraretinal cysts & 7 & 9.86 \\
\hline Persistent subretinal fluid & 2 & 2.82 \\
\hline $\begin{array}{l}\text { Multiple pigmented epithelium } \\
\text { detachment }\end{array}$ & 2 & 2.82 \\
\hline
\end{tabular}

OCT morphological findings 3 months after vitrectomy:

Twenty-five eyes $(35.21 \%)$ showed normal OCT findings (Figure 1). 
ejhm.journals.ekb.eg
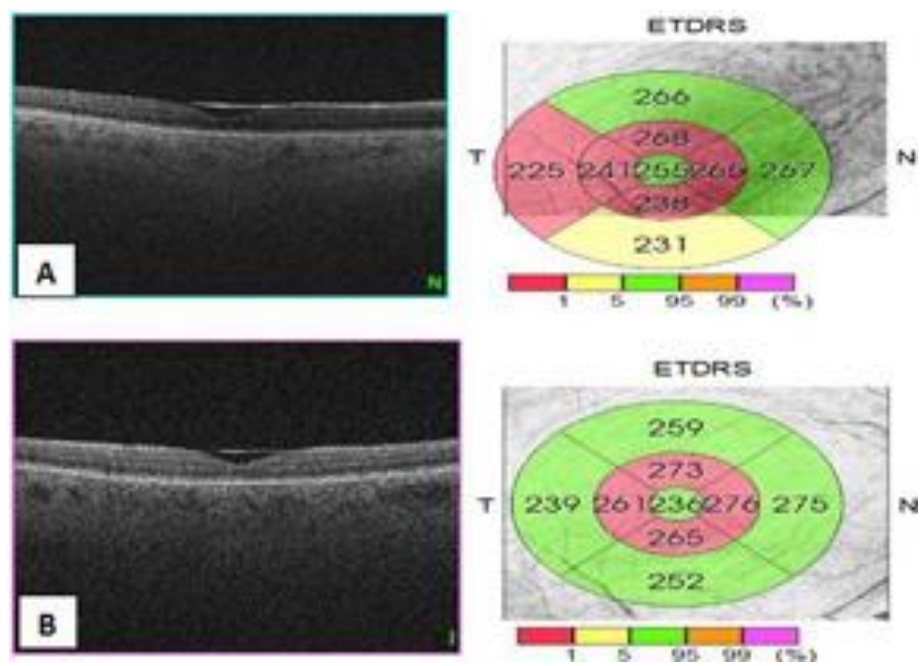

Figure (1): Normal OCT: A. 1 month postoperative. B. 3 month postoperative

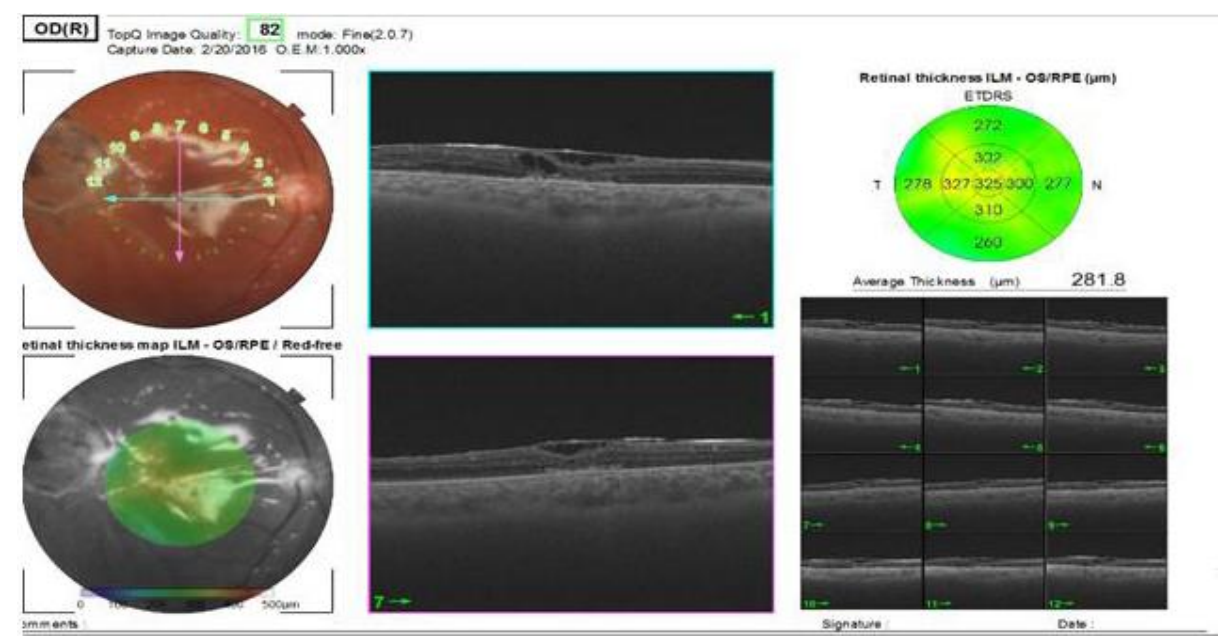

Figure (2): Cystoid macular edema

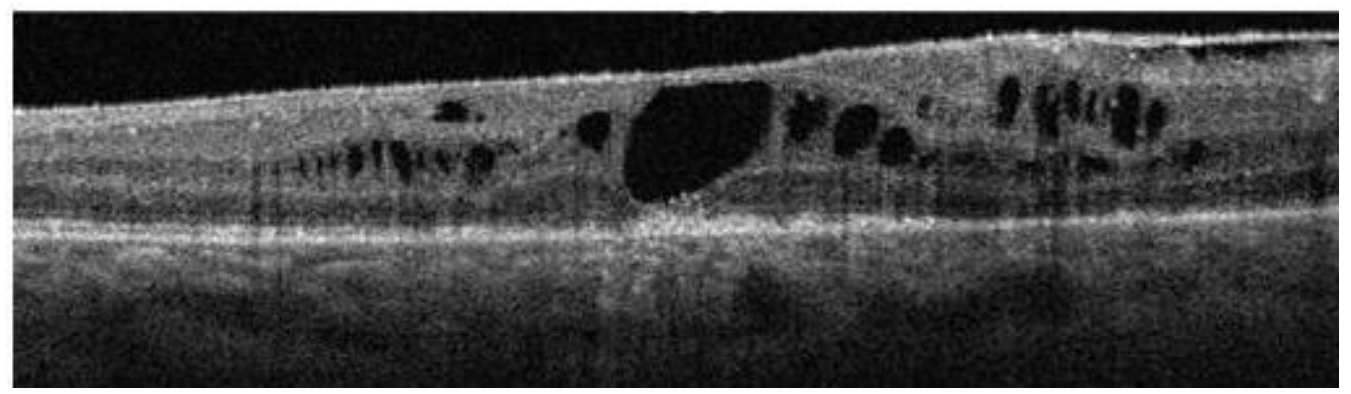

Figure (3): ERM with VMT and CME

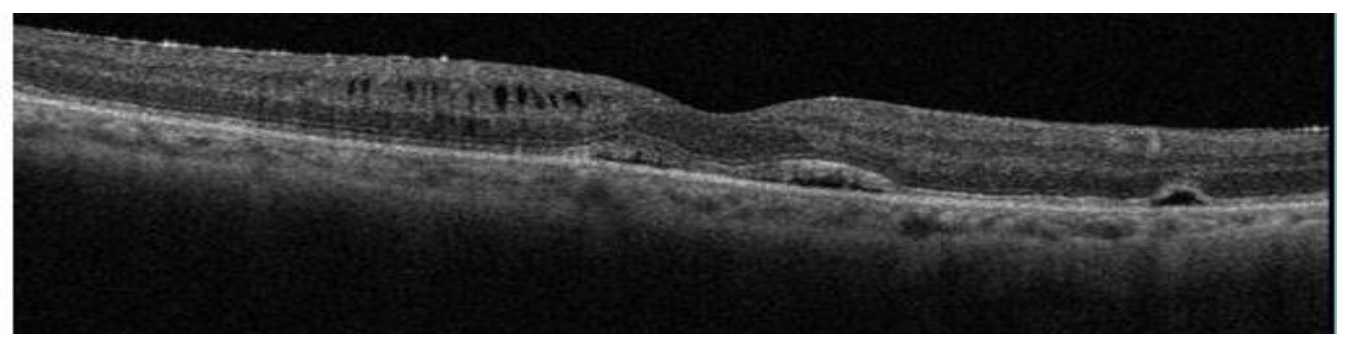

Figure (4): Persistent subretinal fluid 


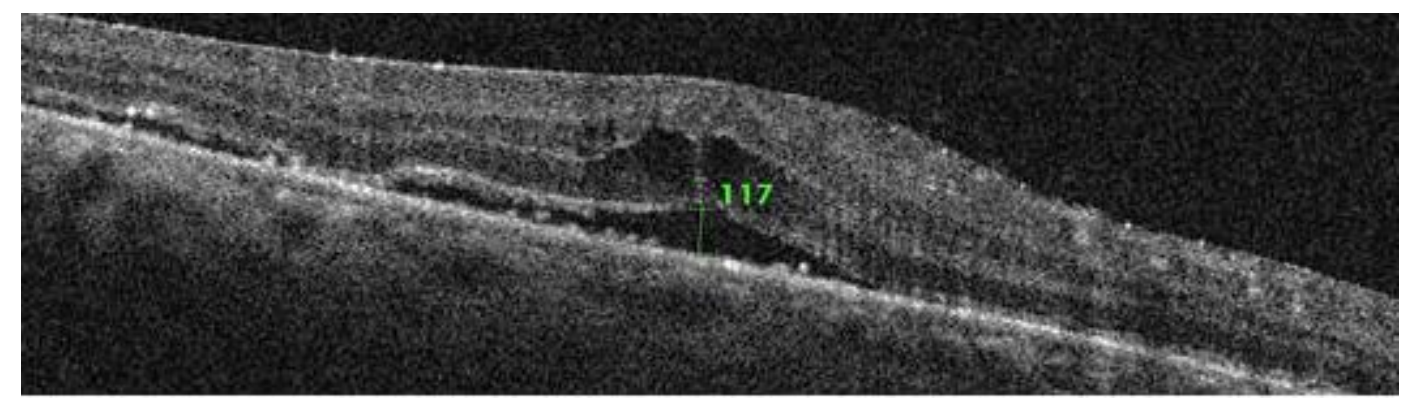

Figure (5): OCT showing sub foveal and juxta foveal shallow serous macular detachment and macular edema with cystic spaces

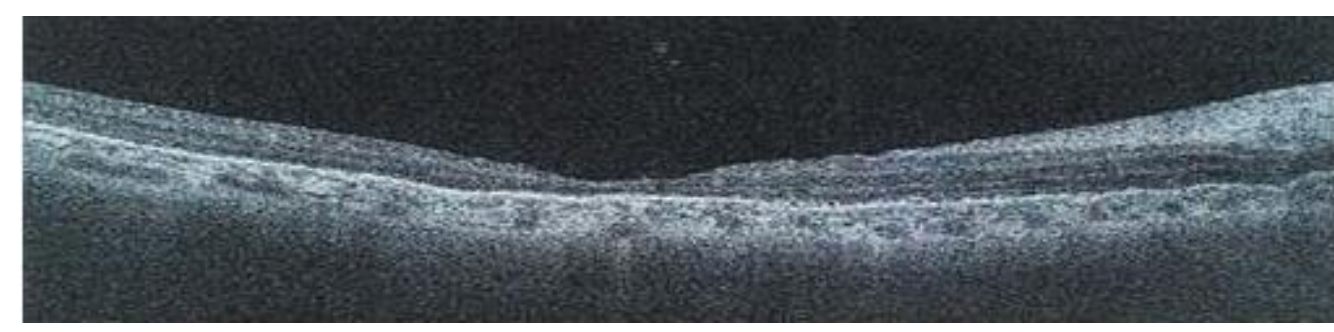

Figure (6): OCT showing Atrophic maculopathy with diffuse thinning of all retinal layers

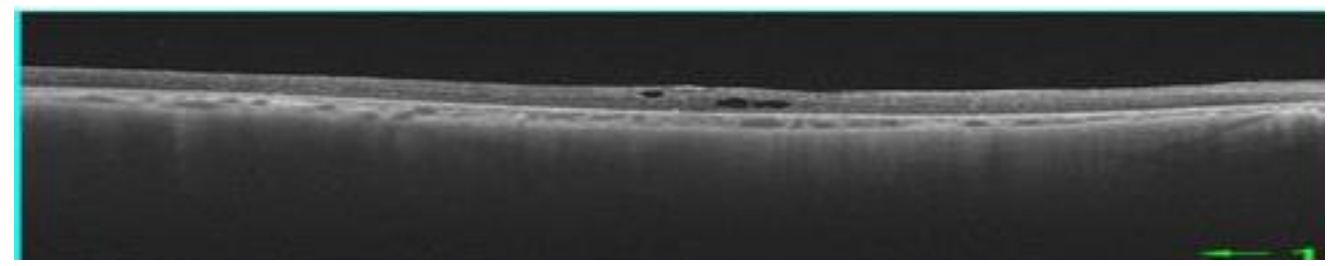

Figure (7): OCT showing sub foveal and parafoveal intra retinal cysts
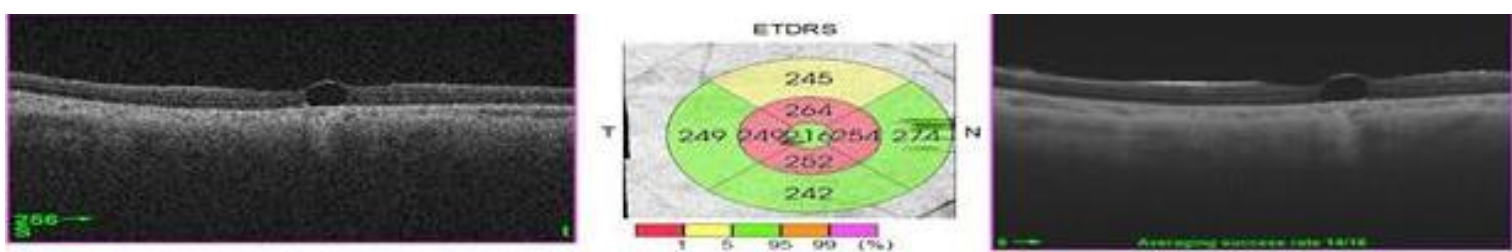

Figure (8): OCT showing subfoveal PFC 1 month (a) and 3 month (b)

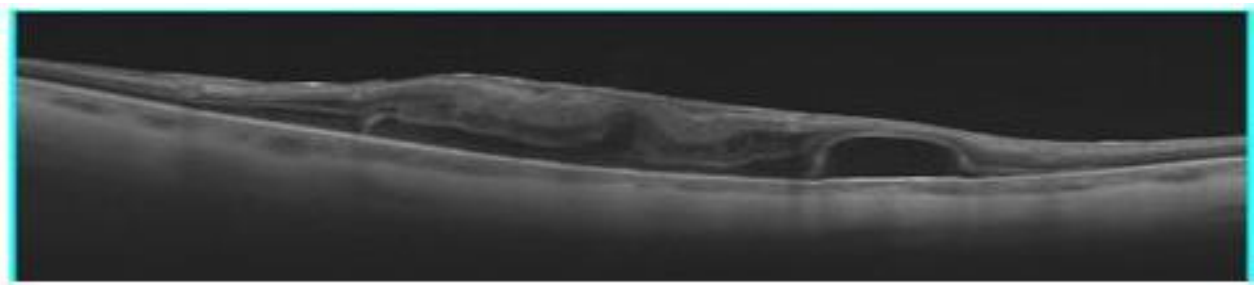

Figure (9): OCT showing parafoveal perfluorocarbon 

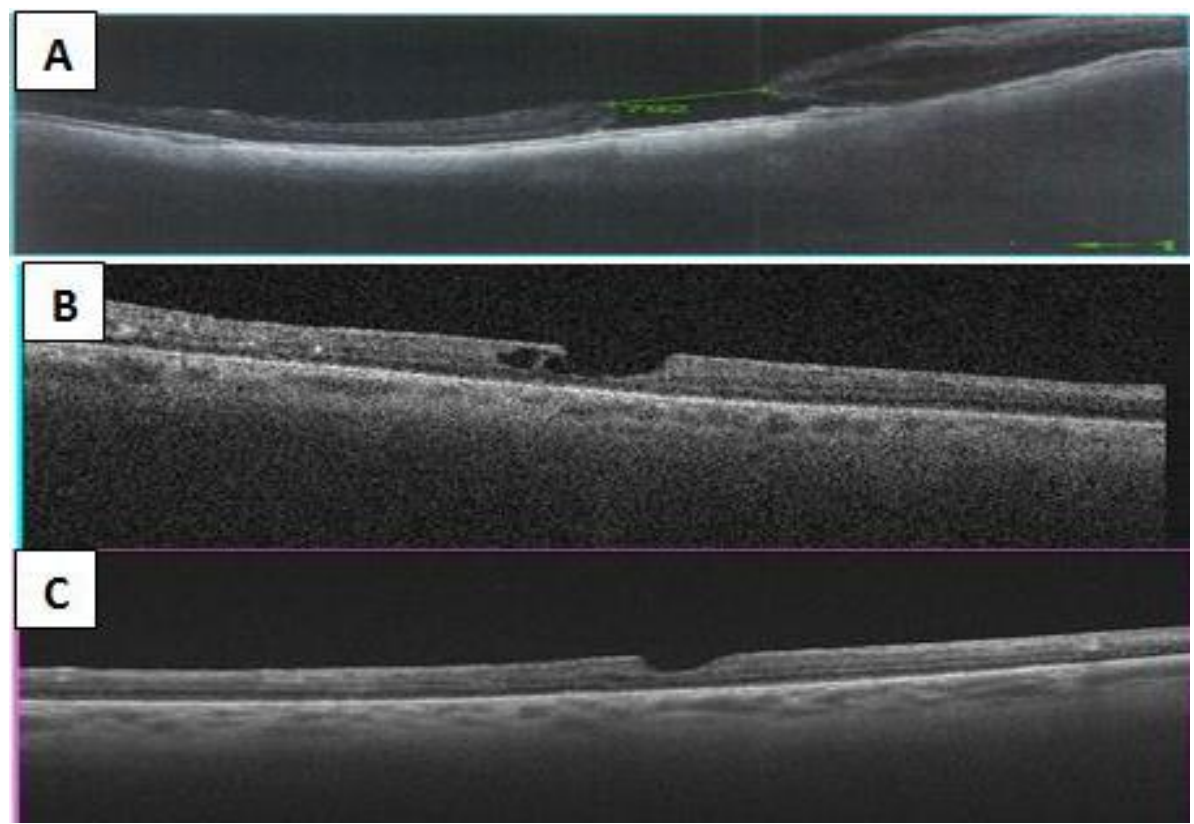

Figure (10): OCT showing full thickness macular hole (a), lamellar macular hole (b) and pseudo macular hole (c)

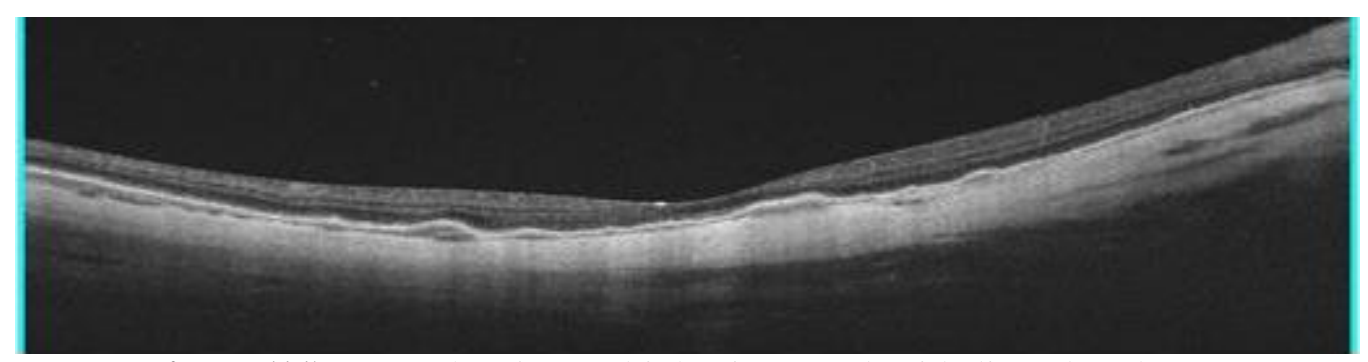

Figure (11): OCT showing multiple pigmented epithelium detachment

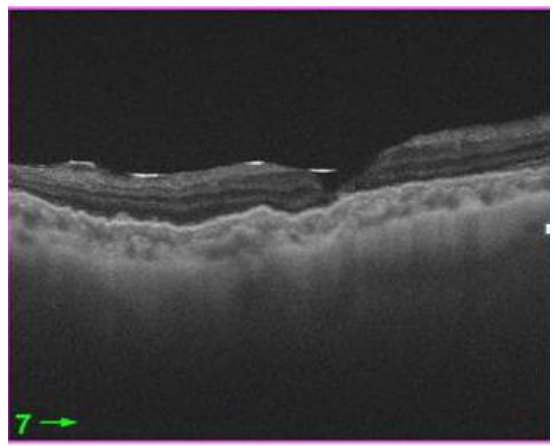

Figure (12): Attenuated IS/OS junction

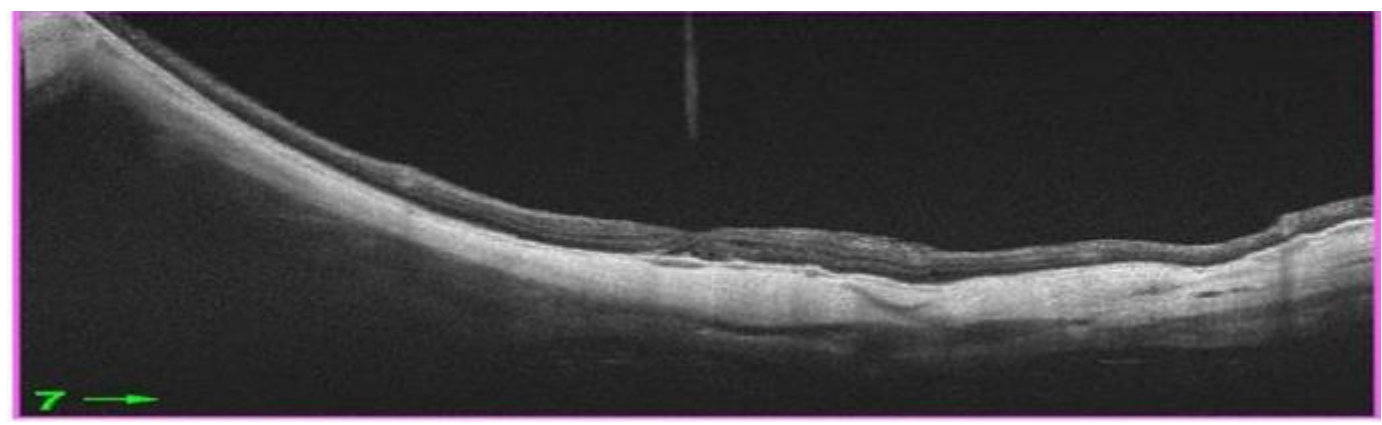

Figure (13): OCT showing corrugated retinal pigment epithelium 


\section{Clinical vs. OCT macular change:}

There is a difference in this research between the macular pathological findings identified by OCT and those found by fundus clinical examination. There were more macular pathological changes identified by OCT compared to those identified by clinical examination.

Table (6): OCT in clinically normal macula

\begin{tabular}{|l|c|c|}
\multicolumn{1}{|c|}{ Findings } & $\begin{array}{c}\text { No. } \\
(\mathbf{n = 2 2})\end{array}$ & \% \\
\hline Macular edema & 7 & 31.82 \\
\hline Serous macular detachment & 2 & 9.10 \\
\hline Atrophic maculopathy & 6 & 27.27 \\
\hline Fine ERM & 5 & 22.73 \\
\hline $\begin{array}{l}\text { Interrupted IS/OS \& RPE- } \\
\text { choriocapillaries complex } \\
\text { irregularity }\end{array}$ & 16 & 72.73 \\
\hline
\end{tabular}

In this study; the macula was clinically normal in 22 eyes (30.99\%), while OCT examination of these eyes was normal in only 7 eyes of 22 eyes $(9.86 \%)$. OCT detected pathological macular changes in 46 eyes of all eyes $(64.79 \%)$, while clinical fundus examination revealed fewer changes in 24 eyes of all eyes $(33.80 \%)$. Table (6) delineates the OCT findings in eyes with clinically normal macula.

\section{DISCUSSION}

It has been revealed that silicone oil has caused retinal damage due to the mechanical status of silicone oil bubbles and SO biochemical toxic responses. ${ }^{(16)}$.

In SO filled eyes, the clinical evaluation of the retinal layers by ophthalmoscope examination was difficult $^{(17)}$. Hence, it was hard to detect changes in the retina during $\mathrm{SO}$ tamponade in comparison to these changes after SO removal ${ }^{(16)}$.

The introduction of SD-OCT which provide in vivo high resolution cross-sectional image of retina, has become an excellent modality to evaluate the macular status and vitreoretinal interface even in SO-filled eyes $^{(\mathbf{1 6}, 17)}$.

In this study, we identified the following retinal morphological changes with the use of Swept source (SS-OCT): attenuated IS/OS junction, macular edema, ERM, persistent subretinal fluid, serous macular detachment, atrophic maculopathy with diffuse thinning of retinal layers, intraretinal cysts and macular hole. This study aimed to assess the role of OCT in detecting the pathological macular changes in response to $\mathrm{SO}$ and to correlate it with clinical findings.

It was noticed in the present research that there was a statistically significant difference between the macular pathological results identified by OCT and those identified by fundus examination since OCT detected more pathological macular changes than clinical fundus examination. Some of the results of the OCT examination were found to be normal in clinical examination.

In this study, the macula was clinically normal in 22 eyes of 71 eyes (30.99\%) while their OCT examination was normal only in 7 eyes of 22 eyes $(9.86 \%)$. Macular edema in 7 eyes of 22 eyes $(31.81 \%)$, serous macular detachment in 2 eyes of 22 eyes (9\%), atrophic maculopathy in 6 eyes of 22 eyes $(27.27 \%)$, fine ERM in 5 eyes of 22 eyes $(22.72 \%)$, interrupted IS/OS junction \& RPE-choriocapillaries complex irregularity in 16 eyes of 22 eyes $(72.72 \%)$, while OCT was normal only in 7 eyes of 22 eyes (31.81\%). These findings were comparable with Rashad et al. ${ }^{(20)}$ study; they found that in SOfilled eyes, the macula was clinically normal in 22 eyes of 51 eyes $(43 \%)$ while OCT examination was normal in only 4 eyes $(18 \%)$. macular edema in 5 eyes of 22 eyes $(22.72 \%)$, serous macular detachment in 3 eyes of 22 eyes (13.63\%) and atrophic maculopathy in 3 eyes of 22 eyes $(13.63 \%)$, fine ERM in 2 eyes of 22 eyes $(9 \%)^{(20)}$.

In this study, in SO-filled eyes OCT detected pathological macular changes in 39 eyes of all eyes (84.78\%) while clinical fundus examination detected some changes in 24 eyes of all eyes (52.17\%) and also these findings were coincident with Rashad et $\boldsymbol{a l}_{.}^{(\mathbf{( 2 0 )}}$ study where OCT revealed macular pathological changes in $88.24 \%$ of cases and only $56.86 \%$ were detected by clinical fundus examination with significant difference in the detection ability of both maneuvers.

Study of Rashad et al. (20) showed that OCT results in 3 of 51 eyes $(5 \%)$ were less than expected by clinical examination. Surgical results in 37 of 51 eyes $(72.5 \%)$ during the removal of SO were consistent with preoperative OCT examination. Surgical plans during the removal of SO have been altered in 38 of 51 eyes (74.5 $\%)$ based on pre-SOR OCT results. While in this research; OCT results in 5 eyes of 46 eyes (10.86 percent) were less than anticipated by clinical examination. Findings during SOR were corresponding to the pre-SOR OCT examination in 41 of 46 eyes (89.13\%).

In this study, ERM was detected in 13 of 46 eyes (28.3\%), 5 eyes with ERM showed vitreomacular traction and tractional macular edema and 8 eyes without vitreomacular traction (VMT). There was clinically significant 
difference with BCVA values only in case of VMT (p-value <0.001). In Rashad et al. (20) $^{(20}$ study, ERM was showed by OCT in $41 \%$ of the examined eyes. In Najapal et al. ${ }^{(21)}$ study, OCT findings showed ERM in (16.3\%) of cases. In Martinez-Castillo et al. ${ }^{(22)}$ study, ERM was found in (10\%) of the PVR eyes. In Bae et al. $^{(\mathbf{2 3})}$, OCT demonstrated ERM in $(26.1 \%)$.

OCT findings in Rashad et al. (20) study, revealed that $41 \%$ of the eyes showed epiretinal membrane, $17 \%$ had macular edema, $13.5 \%$ had macular detachment, $13.5 \%$ showed macular holes, $10 \%$ subrettine membrane and $2 \%$ subretinal membranes. Similar to our study, OCT identified more significant pathogenic changes than fundus examination. This modified surgical steps during SOR and affected the visual outcome predictability after SOR.

In Najapal et $\boldsymbol{a l l}_{\mathbf{.}}^{(\mathbf{2 1 )}}$ study, OCT findings showed ERMs in $16.3 \%$ of cases, macular edema was noted in $21.15 \%$ of cases, $7.6 \%$ of cases had sub foveal fluid, macular thinning at the fovea was noticed in 5.7\% of eyes and $9.61 \%$ of eyes had recurrent RD after SOR (in this study, 4 cases had recurrent RD 1 month after vitrectomy and excluded) and these results were comparable to our results.

Martinez-Castillo et al. ${ }^{(22)}$, reported different lower ERM incidence than the current findings as this study used fundus examination for ERM finding and used OCT only to confirm clinically diagnosed ERM. It also reported eyes that only required surgical ERM removal.

Study by Wickham et al. $^{(5)}$, showed that an intense inflammation occurs in SO-filled eyes at the interface mediated by blood borne macrophages and leading to the creation of epiretinal membranes. It has also been shown that, despite big quantities of $\mathrm{SO}$ in the cell, macrophages of 10 patients contained phagocytised SO and seemed viable. The existence of giant multinucleated cells indicated a chronic inflammatory granulomatous reaction to the intraocular SO. The inflammatory reactions may also cause other macular pathologies as macular edema and lamellar macular hole. The emulsified silicone oil globule is formed owing to the mechanical energy imparted by saccadic movements and the surface tension decrease induced by inflammatory products as the released blood during surgery. The formed emulsified silicone oil globules were seen at the interface during OCT as well.

In the current study, 15 eyes (32.6\%) showed macular edema 3 eyes $(6.5 \%)$ showed localized macular edema, 5 eyes $(10.86 \%)$ showed diffuse macular edema and 7 eyes $(15.22 \%)$ showed cystoid macular edema (CME). After SOR, macular edema resolved in 14 of 15 eyes $(93.3 \%)$. This also could be explained by the effect of postoperative pharmacotherapy as mentioned by Avitable $\boldsymbol{e t}$ al. ${ }^{(13)}$ study.
OCT findings showed macular edema in $17 \%$ of eyes in Rashad et al. ${ }^{\mathbf{( 2 0 )}}$ study and in $21.15 \%$ of cases in Najapal et al.$^{(2)}$ study while in Bae et al.$^{(23)}$ study, OCT demonstrated macular edema in $19.6 \%$. The difference in the percentage of macular edema may be due to the number and the character of the included patients.

The impact of SO on CME remains unclear, although some growth factors have been reported to be concentrated in a small amount between the SO interface and the retina. Increased growth and inflammatory factors related to vascular permeability has been reported and described the changes of macular microstructures that could influence the functional results after $\mathrm{SOR}^{(24)}$.

In Rashad et al. $^{(\mathbf{2 0 )}}$, OCT findings indicated macular holes in $10 \%$ of cases, while in our study, we reported macular hole in 5 eyes (10.9\%); 3 of them high myopic error and 2 emmetropic without pre-operative myopic maculopathy; 2 eyes showed lamellar macular hole, 2 eyes showed full thickness macular hole and 1 eye showed pseudo-macular hole.

In this study, atrophic maculopathy and diffuse thinning of retinal layers occurred in 7 of 46 eyes (15.2\%), which could be explained by the mechanical or vascular affection $\mathrm{SO}$ on the macula.

Many other studies reported a percent around 10\%. In our study, Kubicka-Trzaska et al. ${ }^{(25)}$, study reported macular thinning in $21.7 \%$ of the eyes. Rashad et al. ${ }^{\mathbf{( 2 0 )}}$ study, OCT findings indicated macular thinning in $13.5 \%$, Najapal et al. ${ }^{(21)}$ study, OCT findings showed Macular thinning at the fovea was noted in $5.7 \%$ of the cases. This can be caused by SO-related affection of macular microcirculation.

Benson et al. ${ }^{(26)}$, reported that resolution of subretinal fluid (SRF) took a median of 5.5 months after vitrectomy. In the current study, the mean duration of SO tamponade of the eyes with sub macular fluid was 3.3 months, a period that might be insufficient to achieve complete resolution of SRF. Here, all eyes revealed complete resolution of sub macular fluid at the last follow-up. The clinicians could expect complete absorption of SRF after SOR. This indicates there is no need to maintain $\mathrm{SO}$ tamponade for a prolonged period to achieve complete resolution of sub macular fluid.

The integrity of the foveal photoreceptor layer has been shown a close association with visual function in various retinal diseases as central serous chorioretinopathy, diabetic macular edema, retinal detachment surgery, and macular hole treated with vitrectomy ${ }^{(27)}$.

The restoration of foveal photoreceptors is required for good visual recovery. However, there are few reports describing the status of photoreceptor layer or ELM under SO tamponade $^{(28)}$.

In Bae et al. ${ }^{(23)}$ study, SD-OCT enabled the evaluation of the photoreceptor IS/OS 
junction and ELM under SO tamponade. The restoration of photoreceptor layer or ELM was identified in $2(4.9 \%)$ and 5 eyes (12.5\%), among those with disrupted photoreceptor layer or ELM. The authors identified a significant relationship between final visual outcome and the integrity of both the photoreceptor IS/OS junction and ELM.

\section{CONCLUSION}

Attenuation and interruption of IS/OS and RPE were common OCT findings in 16(34.7\%) eyes. Corrugated RPE was in 4(8.7\%) eyes. Sub macular PFC was reported in $2(4.3 \%)$ eyes.

\section{REFERENCES}

1. Kleinberg TT, Tzekov RT, Stein L, Ravi N, Kaushal S (2011): Vitreous substitutes: a comprehensive review. Surv Ophthalmol., 56(4):300-323.

2. Stalmans P, Pinxten A-M, Wong DS (2015): Cohort safety and efficacy study of siluron 2000 emulsification-resistant silicone oil and F4h5 in the treatment of full-thickness macular hole. Retina (Philadelphia), 35(12): 2558-2563.

3. LA HEIJ EC, Hendrikse F, Kessels AG (2001): Results and complications of temporary silicone oil tamponade in patients with complicated retinal detachments. Retina, 21(2):107-114.

4. Chan C, Okun E (1986): The question of ocular tolerance to intravitreal liquid silicone: a long-term analysis. Ophthalmology, 93(5): 651-660.

5. Lucke KH, Foerster MH, Laqua H (1987): Long-term results of vitrectomy and silicone oil in 500 cases of complicated retinal detachments. Am J Ophthalmol., 104(6): 624-633.

6. Franks WA, Leaver PK (1991): Removal of silicone oil-rewards and penalties. Eye (London), 5: 333-337.

7. Miller JB, Papakostas TD, Vavvas DG (2014): Complications of emulsified silicone oil after retinal detachment repair. Semin Ophthalmol., 29(5-6):312-318.

8. Kiss CG, Richter-Muksch S, Sacu S, Benesch T, VelikayParel $M$ (2007): Anatomy and function of the macula after surgery for retinal detachment complicated by proliferative vitreoretinopathy. Am J Ophthalmol., 144(6): 872-877.

9. Cox MS, Azen SP, Barr CC, Linton KL, Diddie KR, Lai MY, Freeman HM, Irvine A (1995): Macular pucker after successful surgery for proliferative vitreoretinopathy. Silicone Study Report 8. Ophthalmology, 102(12):1884-1891.

10. Christensen UC, la Cour M (2012): Visual loss after use of intraocular silicone oil associated with thinning of inner retinal layers. Acta Ophthalmol., 90(8): 733-737.

11. Roca JA, Wu L, Berrocal M, Rodriguez F, Alezzandrini A, Alvira G, Velez-Montoya R, Quiroz-Mercado H, Arevalo JF, Serrano M (2017): Un-explained visual loss following silicone oil removal: results of the Pan American Collaborative Retina Study (PACORES) Group. Int J Retina Vitreous, 3(1):26-32.

12. Bae SH, Hwang JS, Yu HG (2012): Comparative analysis of macular microstructure by spectral-domain optical coherence tomography before and after silicone oil removal. Retina, 32(9): 1874-1883.

13. Avitabile T, Bonfiglio V, Sanfilippo M, Torrisi B, Reibaldi A (2006): Correlation of optical coherence tomography pattern and visual recovery after vitrectomy with silicone oil for retinal detachment. Retina, 26(8): 917-921.

14. Cazabon S, Groenewald C, Pearce I, Wong D (2005): Visual loss following removal of intraocular silicone oil. $\mathrm{Br} \mathrm{J}$ Ophthalmol., 89(7): 799-802.

15. Herbert E, Habib M, Steel D, Williamson T (2006): Central scotoma associated with intraocular silicone oil tamponade develops before oil removal. Graefes Arch Clin Exp Ophthalmol., 244(2): 248-252.

16. Wickham LJ, Asaria RH, Alexander R, Luthert P, Charteris DG (2007): Immunopathology of intraocular silicone oil: retina and epiretinal membranes. Br J Ophthalmol., 91(2): 258-262.

17. Odrobina DC, Michalewska Z, Michalewski J, Nawrocki J (2010): High-speed, high-resolution spectral optical coherence tomography in patients after vitrectomy with internal limiting membrane peeling for proliferative vitreoretinopathy retinal detachment. Retina, 30(6): 881-886.

18. Tanaka Y, Toyoda F, Shimmura-Tomita M, Kinoshita N, Takano H, Dobashi Y, Yamada S, Obata H, Kakehashi A (2018): Clinicopathological features of epiretinal membranes in eyes filled with silicone oil. Clin Ophthalmol., 12: 194-9.

19. Zoric Geber M, Bencic G, Vatavuk Z, Ivekovic R, Friberg TR (2015): Retinal nerve fibre layer thickness measurements after successful retinal detachment repair with silicone oil endotamponade. Br J Ophthalmol., 99(6): 853-858.

20. Rashad MA, Mohamed AAA, Ahmed AI (2016): Value of optical coherence tomography in the detection of macular pathology before the removal of silicone oil. Clin Ophthalmol., 10: 121-127.

21. Nagpal MP, Videkar RP, Nagpal KM (2012): Factors having implications on re-retinal detachments after silicone oil removal. Indian J ophthalmol., 60(6): 517-522.

22. Martínez-Castillo V, Boixadera A, Distéfano L, Zapata $M$, García-Arumí J (2012): Epiretinal membrane after pras plana vitrectomy for primary pseudophakic or aphakic rhegmatogenous retinal detachment- incidence and outcomes. Retina, 32(7): 1350-1355.

23. Bae SH, Hwang JS, Yu HG (2012): Comparative analysis of macular microstructure by spectral-domain optical coherence tomography before and after silicone oil removal. Retina, 32(9): 1874-1883.

24. Mukai N, Lee P, Oguri M, Schepens C (1975): A long-term evaluation of silicone retinopathy in monkeys. Can J Ophthalmol., 10(3): 391-402.

25. Kubicka-Trzaska A, Kobylarz J, Romanowska-Dixon B (2011): Macular microcirculation blood flow after pars plana vitrectomy with silicone oil tamponade. Klinika Oczna, 113(46): 146-148.

26. Benson SE, Schlottmann PG, Bunce C, Xing W, Charteris DG (2006): Optical coherence tomography analysis of the macula after vitrectomy surgery for retinal detachment. Ophthalmology, 113(7): 1179-1183.

27. Maheshwary AS, Oster SF, Yuson RM, Cheng L, Mojana F, Freeman WR (2010): The association between percent disruption of the photoreceptor inner segment-outer segment junction and visual acuity in diabetic macular edema. Am J Ophthalmol., 150(1): 63-67.

28. Wakabayashi T, Oshima Y, Fujimoto H, Murakami Y, Sakaguchi H, Kusaka S, Tano Y (2009): Foveal microstructure and visual acuity after retinal detachment repair: imaging analysis by Fourier-domain optical coherence tomography. Ophthalmology, 116(3): 519-528. 